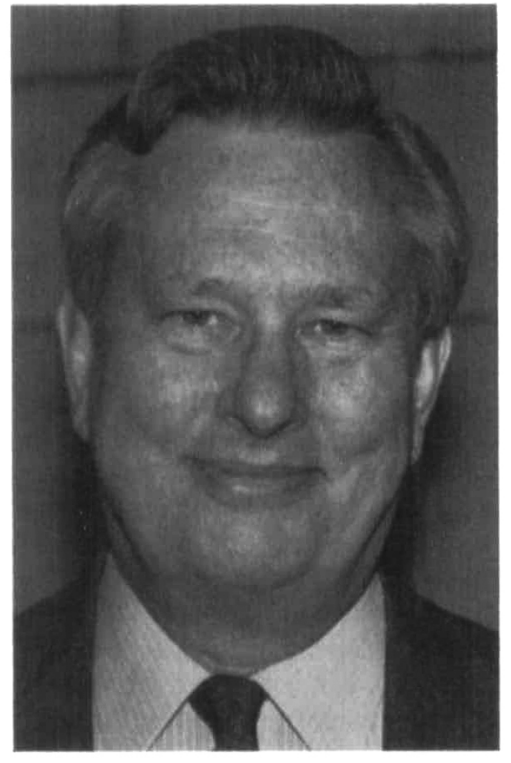

Introduction

The field of materials science and engineering is advancing at a revolutionary pace. It is now generally recognized as being among the key emerging technological fields propelling our world societies into the 21st century. The driving forces for this revolutionary pace are at once social, economic, political and technological. Major changes in materials processing and use patterns are creating requirements for new materials developments, substitutions and associated processes. Never before have materials engineers been able to offer so many options to design engineers in assisting them to reconcile conflicting ideals of efficiency, economy, functionality, durability and aesthetics. With a deep fundamental understanding of structure-property relationships, an increasing selection of materials syntheses, processing and joining technologies, modern computer methods and advanced characterization instrumentation, the materials engineer is more than ever "plugged in" at all steps along the "value-added chain" from engineering designs to manufacturing and to customer service.

Highly developed and developing countries around the world are increasing their investments in technology as a

*Presented December 1, 1987 at the 1987 MRS Fall Meeting, in Boston, Massachusetts, during Symposium $Y$ on Education in Materials Science and Engineering: The Changing Role of University, Industry and Government Interactions.

\title{
Exploiting New Materials Technologies for Competitive Advantage * $^{*}$
}

\author{
Arden L. Bement
}

matter of national policy because of the benefits such investments can bring to both quality of life and national prestige. Consequently, the fraction of the world's technology base contributed by the United States will continue to decline, and the risk of becoming "blind-sided" by technological breakthroughs elsewhere in the world will continue to increase.

\section{Our major national asset to sustained industrial competitiveness and global technological leadership is the research university.}

I believe our major national asset to sustained industrial competitiveness and global technological leadership is the research university. Research universities in the United States have become the envy of the world for the quality of their higher level education and research. With the initiation of the ARPA interdisciplinary laboratories in the early 1960s and the issuance of the COSMAT report in 1973 entitled Materials and Man's Needs, research universities have established multidisciplinary departments of materials science and engineering and universitylevel, interdisciplinary MSE research centers to broaden the participation in materials research by all of the co-lateral disciplines of science and engineering. They have also provided a closer link between theory and experiment and greater access to expensive instrumentation. These changes have greatly increased the quality of graduate MSE talent available to all sectors of our society and have also increased the pace of new materials discoveries.

Yet, in spite of these advances, or perhaps because of them, universities are finding it necessary to evaluate their curricula and research directions more critically now than ever before to address a growing number of interrelated questions such as:

- How much emphasis should be given in a four-year undergraduate curriculum to the total education of the individual at the expense of education in the disciplinary core?

- How much specialization should be incorporated in an undergraduate curriculum in MSE, and how should this be balanced against a unified MSE core?

- What should be the balance between entrepreneurial $R \& D$ activities in close partnership with industry versus conserving the traditional university missions of disseminating knowledge and generating new knowledge? Can these missions be made compatible?

- How much human and financial resource should be invested in fostering an environment of interdisciplinary cooperation across disciplinary departments and major university units versus building greater strength in the disciplines?

- What types of continuing education courses will best serve the needs of 
technical talent in industry and government to upgrade their skills and competencies in a rapidly changing world?

- What new teaching methods will increase the quality and productivity of higher education in the face of ever increasing faculty loading?

These and many other such questions facing research universities must be rationalized in the light of our expanding global competition and interdependency.

I believe, however, it will be helpful to consider current responses by U.S. industry, government and the universities to this changing global environment before addressing educational issues further.

\section{U.S. companies are forced} to take an intensified global view....

\section{Industry Responses}

U.S. companies are forced to take an intensified global view in conducting $R \& D$, gathering information, forecasting technologies, planning markets, developing new businesses and finding superior material sources.

- In markets where R\&D timetables for new product developments are shrinking, companies are decentralizing their $R \& D$ laboratories and replacing bench scientists with "huntergatherer" technologists.

- While industrially funded R\&D has been on the rise, the basic research fraction of this R\&D has been contracting rapidly, and industry is more and more looking to universities and national laboratories for such research.

- Industry is also taking a more open stance in acquiring new technologies and is entering into alliances, consortia, joint ventures, minority equity agreements and other such partnerships around the world to augment internal developments and knowhow.

- Some transnational companies are adjusting their technology acquisition strategies to the technology policies of foreign governments in order to broaden their acquisition base of superior technologies.

One might say that U.S. companies are becoming more Japanese-like in acquiring new technologies and are focusing their technical resources to adapting and integrating these tech- nologies to meet the requirements of the marketplace in the shortest time and at least cost.

\section{Government Responses}

Both federal and state governments have enacted a variety of de facto technology policies to improve the international competitiveness of U.S. industry, improve domestic economic development, and increase the pace of new job creation.

Early policies over the past decade have stressed $R \& D$ tax credits for increased $R \& D$ investments and accelerated depreciation schedules for $R \& D$ equipment. These policies have been complimented by small business setaside programs, modification of antitrust laws to permit limited $R \& D$ partnerships, and the assignment of federal intellectual properties to universities and small business firms.

During the current Administration, both federal and state governments have increased direct $R \& D$ investments in emerging technologies that can impact industrial innovation and competitiveness. Such programs in the field of materials science and engineering now consist of a wide spectrum of new university centers and initiatives in advanced composites, high technology ceramics, compound semiconductors, high temperature alloys, net shape fabrication, surfaces and interfaces and other such industrially important materials technologies.

Among the federal agencies, the National Science Foundation has been most active in fostering a closer interaction between universities and industry through the NSF Engineering Research Centers and Industry-University Cooperative Research Centers. Also, the Materials Research Laboratories that already exist and the Basic Science and Technology Centers and Biological Centers announced for NSF awards beginning in FY88 are attracting industry's attention and participation.

The Department of Defense has followed suit with University Research Initiatives and targeted DARPA basic technology projects to leverage new technologies of interest to DOD.

Finally, nearly 40 states have established university-industry initiatives to leverage federal $R \& D$ investments in addressing regional strategies to attract new businesses and create new jobs.

An included objective in these and other federal and state programs is to improve the availability of new technology to small- and medium-size businesses because of their agility in creat- ing new jobs and bringing new technological products, processes and services into the marketplace. This objective is being met through a variety of strategies which include small business set-aside programs in the mission agencies, SBA financing programs, the Small Business Innovation Research Program (SBIR) and Small Business Development Centers in the various states. These programs, which focus on the technology needs of individual businesses, are being further augmented by university economic development (EDA) centers and trade adjustment assistance centers funded by the Department of Commerce.

Pending legislation tied to the trade bill would expand the Commerce Department's role by renaming the National Bureau of Standards the National Institute of Standards and Technology and assigning it new program responsibilities to include national technology transfer centers, a national technology policy development program, industrial extension services and an advanced technology program or "civilian DARPA." All these programs are, again, intended to focus on the technology needs of small- and medium-size businesses and to involve both universities and federal laboratories in implementing the planned services.

\section{The National Science Foundation has been most active in fostering a closer interaction between universities and industry...}

The Technology Transfer Act of 1986 and the President's Executive Order 1096, dated April 10, 1987 and entitled Facilitating Access to Science and Technology, have substantially facilitated federal technology transfer through the establishment of a Federal Laboratory Consortium. Consisting of a network of laboratory representatives from over 350 federal laboratories, the consortium addresses technology transfer issues, increased funding and administrative support, increased numbers of user facilities, and broadened policies of federal involvement in proprietary research.

In addition, the National Aeronautics and Space Administration has long had a technology utilization program which now includes nine NASA field centers, ten NASA industrial application cen- 
ters, a Computer Software Management and Information Center, application engineering teams, and NASA Tech Briefs - all aimed at applying aerospace technology to solving public and private sector problems.

One might argue that with the present plethora of government programs we should be able to rebuild the bridge that has long been out between the generation of new technologies and the application of these technologies for competitive advantage. Some gaps, however, still remain.

First, many of the new models focus primarily on startup issues and plurality of support and have not yet matured to the stage of addressing long-term financial sustainability, fragmentation of effort, and excess redundancy. Second, in some instances the gaps are still too broad for industry to bridge with available technical talent. And furthermore, federal technology transfer programs seem to be designed more from the viewpoint of the provider than that of the receiver.

Technologies developed at universities, federal laboratories and central industrial laboratories require considerable refinement and risk reduction before proof of competitive advantage can be demonstrated. This is a messy process, but the key to competitive advantage is to complete this process at the lowest cost and in the least time. From the receiver's point of view the technology transfer process does not end until the product is sold. The receiver, therefore, might look upon technology transfer as consisting of three stages: technology acquisition, technology adaptation and technology integration. The latter two stages contain most of the risk reduction, financial investment and development lead time. Successful technology transfers usually entail continuing interaction between the provider and receiver beyond the early technology acquisition stage.

This risk-reduction process, if unfocused can involve duplicative efforts throughout an industry during the early stages of market development, the socalled "pre-competitive" stage. Such efforts can be highly wasteful of scarce $R \& D$ resources within a company, an industry and indeed a nation. It is during this so-called "pre-competitive" stage that the Ministry of International Trade and Industry (MITI) in Japan plays a national leadership role in shortening the lead time for market entry for advanced technologies.

The method used by MITI is relatively straightforward: 1 . involve industry in determining the advanced technology development and investment priorities, 2 . share the investment with industry on a "shared risk-shared benefit" basis, and 3 . terminate government investment when the program goals are achieved (i.e., when competitive forces can best take over). Managed properly, such an approach can increase competition by increasing the numbers of potential competitors with capabilities in the emerging technology. Such a model, however, requires an acceptable working definition of "precompetitive," careful selection of the critical technical barriers to be overcome, and diligence in terminating government investments when competitive forces take hold.

Policies that address the federal role in the pre-competitive stage of technology risk reduction are currently under active study by the MacKay/Packard Technology Task Force of the House Committee on Science, Space and Technology. The establishment of Sematech, which will focus on generic or precompetitive processing and instrumentation technologies for submicron microelectronic device structures, will be precedent setting in establishing industry-government-university alliances for conducting $R \& D$ at the precompetitive stage of commercial technology exploitation.

\section{University Responses}

U.S. research universities have responded to industry's needs for top talent and new technologies by giving greater recognition to competitiveness as a national imperative. Over the past decade universities have increased their emphasis on university-industry joint R\&D programs through research consortia, technology parks, entrepreneural incubation facilities and campusaffiliated technology development institutes.

Universities have participated in state-funded, technology outreach programs aimed at small- and mediumsized businesses. They have established new programs in advanced manufacturing, robotics, advanced sensors, instrumentation and control, computeraided engineering, advanced computational technologies, etc., to provide the engineering talent needed for industrial modernization.

Universities have also increased their use of industrial visiting and advisory committees to address industry's needs and to develop improved communications and working relationships across university-industry interfaces. Further- more, universities have expanded realtime video broadcasting and off-campus education programs that address the need of industry for continuing education.

\section{U.S. universities have demonstrated a high level of sophistication in accommodating industry's needs...}

These and many other university initiatives have greatly expanded the numbers of ways the public and private sectors can tap the intellectual resources at universities. However, such initiatives have also exacerbated faculty loading and have intensified concerns among academic faculties about the preservation of academic traditions and values and the focus on basic research. Nevertheless, U.S. universities have demonstrated a high level of sophistication in accommodating industry's needs within these constraints. As a result the synergy that now exists across university, industry and government interfaces in the United States is probably higher than in any other country in the world, with the possible exception of West Germany.

\section{Industrial and Governmental Needs and Expectations for Materials Education}

What then are the industrial and governmental needs and expectations for materials science and engineering talent in the world of accelerating technological development and change? Since materials science and engineering is a crosscutting, enabling technology among most of the emerging technologies, what special educational requirements does that place on materials scientists and engineers? I would suggest specific goals (listed in Table I) for an undergraduate curriculum in materials science and engineering. While they seem to be a tall order, I have reviewed recent curriculum changes in a few leading research universities that are meeting most if not all of these general criteria.

At the graduate level, the field of materials science and engineering has long been at the vanguard of interdisciplinary education. University-level MSE research centers are enriching the education of MSE graduate students by exposing them not only to outstanding 


\section{Table I. Goals for an Undergraduate Curriculum in Materials Science and Engineering \\ 1. Provide a balanced preparation in mathematics and the basic sciences, the engineering sciences, computer skills, engineering design, humanities and social sciences; unified preparatory courses in materials science; and engi- neering and specialized courses in an area of materials concentration.}

2. Provide a single core curriculum in materials properties, materials design and processing to include metals, ceramics, semiconductors and polymers so that graduates can move into a wider field of career choices, but include elective subjects in the junior and senior years in areas of materials concentration for students who are sure of their career choices.

3. Intensify the development of communication skills, leadership and teaminterpersonal relationships as an integrated part of the total educational experience. While some English remediation may be required in the freshman year, the practice of English composition should be stressed in as many courses as possible through the assignment of state-of-the-art reviews, laboratory reports, term papers, etc.

4. Allow students to use electives to broaden their education in cognate fields of the basic and engineering sciences if that is their choice.

5. For students pursuing a materials engineering program, provide greater indoctrination in the history of engineering, engineer role models and the role of engineers as "change masters" in a highly flexible society.

researchers from other disciplines, but also to new ideas and concepts from expanded peer interactions. This trend should continue, complemented with specific instruction in the techniques and methods of working across disciplines. PhD programs in MSE should require two three-course sequences in such cognate fields as mathematics, physics, chemistry, computation sciences and theoretical and applied mechanics. Another requirement should be a demonstrated reading skill in at least one foreign language.
University engineering degree offerings at the BS, MS and PhD levels are currently satisfying most but not all of the needs of industry and government. There is a growing need for engineers with higher level education in the solution of complex engineering problems requiring specialized analytical and computational skills and a broad education in the so-called "clinical" aspects of professional engineering such as:

- Technology management including technology forecasting and strategic planning,

- Project management,

- Statistical and deterministic risk management,

- Quality engineering,

- Systems engineering,

- Material management,

- Engineering economics,

- Decision science,

- Legal and ethical conduct,

- Environmental engineering management,

- Information and data base management, and

- Technology policy.

I believe the need for highly trained talent in these subjects - which are central to the management of complex engineering systems in both industry and government - will grow. Furthermore, these subjects deserve the intellectual enquiry and analytical discipline that an engineering faculty can provide. One might question, then, whether the time has come in the United States to introduce a professional doctorate of engineering degree equivalent in standing to the MD, JD and DBA degrees, which focus on the "clinical" skills of the profession.

While such a concept has been advanced by others over the years, it has been impeded by many barriers. First of all, the waters have not been sufficiently tested to gauge the demand and career success of such a degree. Furthermore, the source of research sponsorship and peer-reviewed journals are not well developed. Finally, such new degree programs strain already scarce discretionary resources at universities and compete with more favored programs which are more highly leveraged with respect to potential research support.

Nevertheless, some research universities are introducing courses and academic options in some of these fields to satisfy growing demands. I believe that some of the smaller engineering schools will venture into this niche in the educational market within the next decade and will provide a new breed of leaders for industry and government engineering management roles.

In conclusion, I would like to stress that both industry and government leaders alike are preaching the gospel of change to their employees. Success in today's world requires being more forward looking in analyzing the future, anticipating change, and mitigating the traumas of change. These lessons apply equally well to the field of materials science and engineering.

Arden L. Bement Jr. is vice president of technical resources, TRW Inc., Cleveland, Ohio. In this position he identifies and evaluates emerging technologies and recommends product, material, and process development projects. He also develops special relationships with selected universities and helps recruit key individuals in new technologies of interest to TRW. Bement is chairman of the National Research Council Commission for Engineering and Technical Systems, the National Bureau of Standards Statutory Visiting Committee, and is a member of several boards and committees of the National Research Council and National Academy of Engineering.

Advertisers in this issue: Applied Science and
Technology

Brimrose back cover

General lonex inside front cover

High Voltage Engineering Europa 3

Howard Associates 20

Ion Tech 11

Janis Research

JEOL inside back cover

Siemens

South Bay Technology

13

University of California, Berkeley

VSP (VNU Science Press)

Carl Zeiss, Inc. 